\title{
Avaliação de dialetos brasileiros: o sotaque ${ }^{1}$
}

Jânia M. Ramos

Universidade Federal de Minas Gerais

\section{Abstract}

This paper presents scores of attitude tests applied in five Brazilian cities: Belo Horizonte, Rio de Janeiro, Florianópolis, João Pessoa and Porto Alegre.

The results made possible the identification of a narrow relationship between self-confidence and cultural identity: the more people in a city are aware of the difference between their dialect and the dialect used by the media the proudes they are of their accent. It is exactly this accent which received the highest scores of acceptability by the speakers of other accents. 
$\mathrm{N}$

este artigo apresento os resultados da primeira etapa de uma pesquisa sobre atitude lingüística. O trabalho realizado até aqui teve por objetivo responder à seguinte pergunta: como os falantes de cinco estados brasileiros reagem aos diferentes sotaques? Esta questão está intimamente ligada a uma outra, que tem sido objeto de atenção e debate entre sociolingüistas brasileiros, a saber: qual é o dialeto-padrão do nosso país?

A meu ver, os resultados de testes de atitude constituem um instrumento útil na busca de respostas a ambas as questões, tendo em vista a reconhecida existência de consenso quanto às normas lingüísticas de uso dentro de uma comunidade de fala.

$\mathrm{O}$ presente artigo subdivide-se em quatro partes. Na primeira são definidas as noções de atitude e sotaque. Na segunda é descrita a metodologia utilizada. Na terceira são apresentados os resultados. E por último, a conclusão, abordando tópicos de pesquisa futura e limitações da metodologia utilizada.

\section{CONCEITOS DE ATITUDE E SOTAQUE}

Será adotada aqui a seguinte conceituação de atitude: "Atitude é caracterizada como uma resposta incorporada ao indivíduo, resposta esta que tende a mediar ou conduzir as respostas avaliativas mais abertas de um sujeito em relação a um objeto ou conceito.” (Fishbein (1965), citado por Santos (1980:19)). ${ }^{2}$

Tal conceituação permite a utilização de questionários como instrumento de avaliação da atitude do falante. É deste instrumento que tratarei a seguir. 
Por sotaque entenda-se aqui traços indicadores de processos fonológicos gerais e de padrões prosódicos. ${ }^{3}$

\section{A METODOLOGIA}

Dois questionários foram aplicados. ${ }^{4} \mathrm{O}$ primeiro compõe-se de 48 perguntas respondidas por 60 falantes, em média, de cada um dos cinco estados investigados. São eles: Rio Grande do Sul, Santa Catarina, Minas Gerais, Rio de Janeiro e Paraíba. Foram consultados informantes de duas faixas etárias (14-15 anos) e (25 a 40 anos), de classe média. A definição da classe teve como critério o tipo de residência. ${ }^{5}$ Foram obtidos 17.040 dados.

Foram formuladas questões cujas respostas apresentavam cinco opções. Trata-se de uma escala semântica diferencial (Osgood, Suci e Tannenbaum, 1957). Vejamos um exemplo:
A língua portuguesa é:
simples: : : complicada

Esse questionário constitui uma adaptação do questionário aplicado por Almeida (1979) a falantes da cidade de Belo Horizonte. A opção por manter um questionário semelhante decorreu de seu caráter tecnicamente bem elaborado e da possibilidade de comparar os dados de uma mesma população após um intervalo de quase vinte anos. As adaptações feitas consistiram na inserção de perguntas que permitissem avaliar a linguagem veiculada em noticiários de TV, considerada representativa do padrão culto atual. Foi tomada como objeto a fala dos apresentadores do Jornal Nacional, no período de março/abril, por ser este o noticiário de maior índice de audiência no país. As questões formuladas sobre este último item foram: 
A fala dos jornalistas do Jornal Nacional reflete a fala da minha região. concordo: :discordo

Eu falo como os apresentadores do Jornal Nacional, da Globo. concordo: :discordo

O cálculo foi feito da seguinte forma: anotou-se quantos falantes marcaram cada um dos cinco espaços, tal como aparece a seguir:

Gente da roça fala melhor que gente da cidade.

concordo

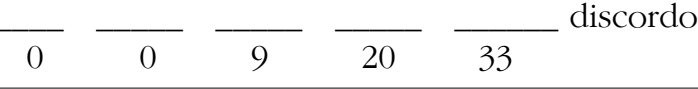

No exemplo acima, houve zero marcas no primeiro espaço à esquerda, 0 marcas no segundo espaço, 9 marcas no terceiro, 20 marcas no quarto e 33 no quinto, somando um total de 62 marcas, o que indica que 62 informantes responderam àquela questão.

As marcações foram classificadas em três grupos: favoráveis (as marcas referentes aos dois espaços à esquerda), neutras (as do terceiro espaço) e desfavoráveis (as do quarto e quinto espaços), chegando-se, respectivamente, às seguintes porcentagens: 0\%, 21,6\% e $78,4 \%$.

Em seguida os valores correspondentes a cada questão de cada estado $^{6}$ foram comparados. E são estes últimos resultados que aparecem nos gráficos e tabelas abaixo.

O segundo questionário visava a avaliar atitudes a partir de amostras dos diferentes dialetos. O informante ouvia um fragmento de entrevista, de aproximadamente três minutos de gravação sobre diversões (viagens, cinema, etc.), com falante de nível superior e lhe era solicitado identificar (1) a origem geográfica do falante; (2) sua profissão; (3) se aquele modo de falar lhe era agradável ou desagradável; (4) se aquela maneira de falar era correta ou incorreta; 
e, finalmente, (5) se havia algum falante, dentre aqueles ouvidos na fita, que não apresentava sotaque algum. Um total de 31 informantes mineiros respondeu ao segundo questionário, o que perfez um total de 775 dados.

O formato da folha de resposta referente a cada um dos cinco fragmentos de entrevista gravados aparece abaixo. O informante respondia imediatamente após ouvir cada fragmento.

Falante 1:

\section{Origem:}

( ) Catarinense Profissão:

( ) Paranaense ( ) Advogado

( ) Mineiro ( ) Médico

( ) Paulista ( ) Comerciante

( ) Paraibano ( ) Faxineiro

( ) Carioca ( ) Jornalista

Para você esse modo de falar é:

( ) Maranhense

Esse modo de falar é:

( ) agradável

( ) desagradável

( ) correto

( ) incorreto

A última pergunta deste questionário foi a seguinte:

Dos falantes acima, qual fala sem sotaque algum? Assinale: (1), (2), (3), (4), (5), (6), (nenhum).

Passemos então aos resultados.

\section{OS RESULTADOS}

\subsection{Questionário aplicado em cinco capitais}

Passarei agora a comentar os resultados de apenas um subconjunto das questões respondidas. Vejamos inicialmente a questão que avalia a relação entre dialeto rural e urbano. 
Gente da roça fala melhor que gente da cidade.

concordo: : : :discordo

Os resultados aparecem na tabela 1 .

Tabela 1: Avaliação, por estado, do dialeto rural como padrão brasileiro

\begin{tabular}{|l|cc|cc|cc|cc|cc|}
\hline & \multicolumn{2}{|c|}{ SC } & \multicolumn{2}{c|}{ MG } & \multicolumn{2}{c|}{ PB } & \multicolumn{2}{c|}{ RS } & \multicolumn{2}{c|}{ RJ } \\
\cline { 2 - 13 } & № & $\%$ & № & $\%$ & № & $\%$ & № & $\%$ & № & $\%$ \\
\hline Favorável & 4 & 7 & 2 & 3.7 & 1 & 1.6 & 3 & 5 & 00 & 0 \\
\hline Desfavorável & 45 & 80.6 & 45 & 84.8 & 55 & 88.6 & 51 & 84.6 & 53 & 78.4 \\
\hline Total & 57 & & 53 & & 62 & & 59 & & 62 \\
\hline
\end{tabular}

É consensual a rejeição do dialeto rural como padrão/modelo de fala no Brasil: acima de 78\% em todos os estados. A porcentagem de aceitação tem em Santa Catarina seu índice máximo (7\%) e seu índice mínimo no Rio de Janeiro (0\%).

Seria interessante testar falantes da zona rural em relação a esse item. Se se tiver em conta que a semelhança de atitude em relação ao que é padrão constitui um critério definidor do que seja uma comunidade lingüística, a resposta de falantes da zona rural poderá funcionar como uma orientação em relação ao ensino de língua materna nas escolas rurais: se aqueles falantes assumem ou não os mesmos padrões dos falantes urbanos, isto é, se fazem parte ou não da mesma comunidade de fala. No primeiro caso, o ensino da línguapadrão enfrentará menos barreiras do que no segundo.

No presente trabalho, conforme já mencionado, apenas falantes urbanos foram testados.

A próxima questão busca verificar se, na opinião do falante, o dialeto em foco deve ser considerado um modelo para os falantes de diferentes regiões do país. Os gráficos 1 e 2 mostram os índices de aceitação dos cinco dialetos. As perguntas relevantes aparecem 
abaixo. Cada uma foi feita em diferentes momentos do questionário; evitou-se fazê-las uma após a outra, por razões óbvias.

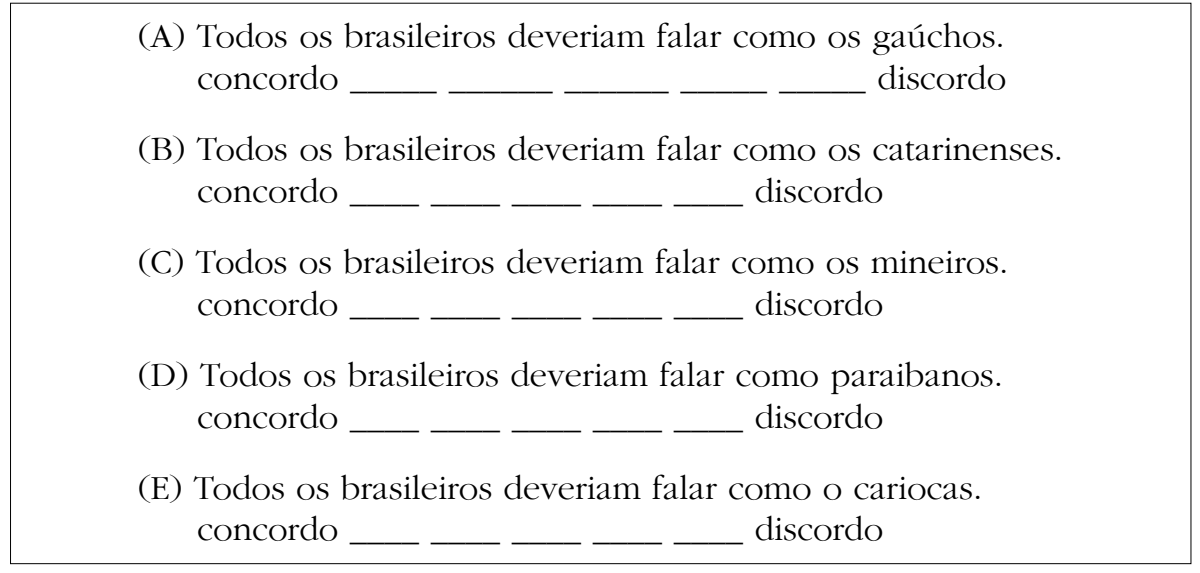

Os resultados referentes aos cinco dialetos aparecem no gráfico 1.

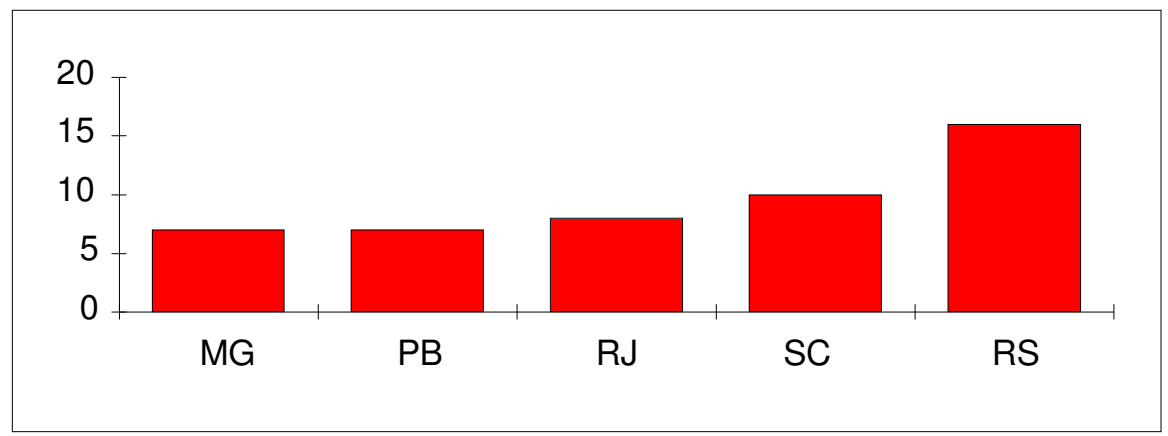

Gráfico 1: Média dos índices de aceitação de cinco dialetos brasileiros por todos os falantes pesquisados.

O dialeto mineiro e o paraibano são os menos aceitos, respectivamente, 6,5\% e 7\%. Muito próximo está o dialeto carioca (8,5\%). Há vinte anos, a aceitação desse último era maior (19,9\%, cf. Almeida, 1979:273), o que possivelmente indica perda do estatuto de capital 
cultural do país por parte da cidade do Rio de Janeiro. Ainda bastante próximo do dialeto carioca está o dialeto catarinense (10,3\%). O maior índice é alcançado pelo dialeto gaúcho (16,5\%).

Vê-se ainda nesse gráfico um alto grau de rejeição a todos os dialetos testados quanto a poderem ser considerados "um modelo a ser seguido por todos os brasileiros": nenhum dos dialetos alcança um índice superior a 50\%. A meu ver, isto não anula a aferição de diferentes graus de prestígio dos diferentes dialetos. Possivelmente a formulação das questões (A-E) contribuiu para obscurecer a avaliação por parte do informante: ao enfatizar um caráter prescritivo através do modalizador "deveriam", o informante foi colocado numa situação de quem, ao concordar com a afirmação, estaria disposto a abrir mão de seu próprio dialeto.

Vejamos agora uma comparação entre o índice de aceitação dos diferentes sotaques pelos respectivos falantes, isto é, o índice de aceitação do dialeto carioca pelos cariocas, do dialeto gaúcho pelos gaúchos, e assim sucessivamente.

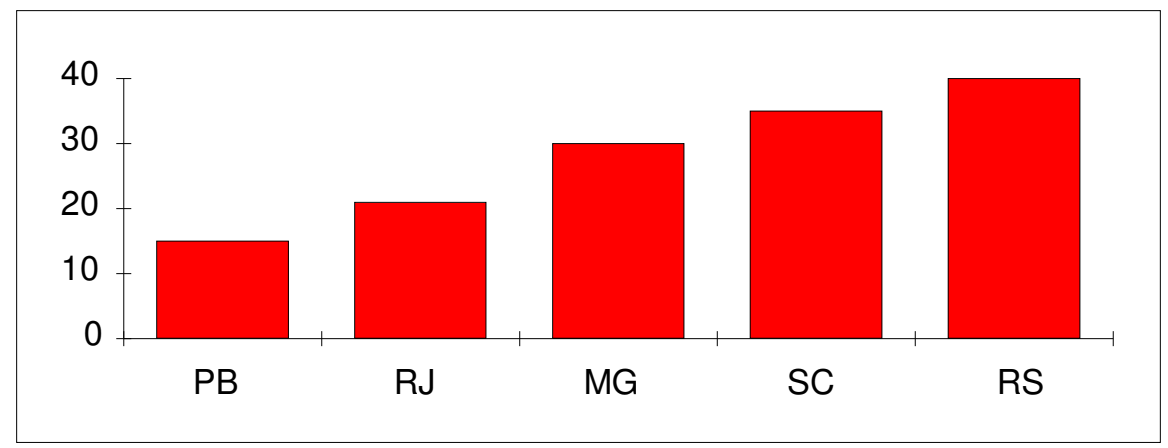

Gráfico 2: Índice médio de aceitação do próprio dialeto como padrão brasileiro pelos falantes de cada estado.

Como se pode ver, o estado que mais positivamente avalia seu dialeto é o RS. A porcentagem de opiniões favoráveis chega a 47.6\%. O estado que menos aceita seu próprio dialeto é a Paraíba, apenas 
13\%. Certamente o prestígio externo, advindo da comparação dos níveis de desenvolvimento sócio-econômico das diferentes regiões, parece refletir-se na avaliação dos respectivos dialetos pelos próprios falantes. Se assim for, RS e PB representariam aqui os extremos numa escala de desenvolvimento, no imaginário dos brasileiros.

Veja-se também que cariocas e paraibanos apresentam índices bem próximos. Até que ponto a crise social que afeta o RJ não estaria afetando a auto-imagem dos cariocas? Outro resultado interessante é que o dialeto mais aceito pelos próprios falantes (isto é, o dialeto gaúcho) é também o mais aceito pelos demais. Até que ponto a aceitação desse dialeto pelos falantes das outras regiões influencia sua aceitação por parte dos próprios falantes? Até que ponto a aceitação de um dialeto espelha de modo transparente a aceitação por parte dos falantes da situação político-social da respectiva região? Estas são questões que certamente só poderão ser respondidas com a ajuda de uma análise desenvolvida no âmbito da psicologia social. E esta é uma tarefa a ser realizada. Podemos, por enquanto, fazer apenas algumas conjecturas, como as apontadas acima.

Encaminhando-se na direção de se definir qual seria o dialetopadrão brasileiro, foram discutidas as respostas referentes à ausência de sotaque. A questão relevante aparece abaixo, acompanhada dos respectivos resultados. Veja-se a tabela 2, a seguir:

\section{Eu falo sem sotaque algum.}

concordo: : :discordo

\begin{tabular}{|l|rc|cc|cc|cc|cc|}
\hline \multirow{2}{*}{} & \multicolumn{2}{|c|}{ MG } & \multicolumn{2}{c|}{ RS } & \multicolumn{2}{c|}{ RJ } & \multicolumn{2}{c|}{ SC } & \multicolumn{2}{c|}{ PB } \\
\cline { 2 - 12 } & № & $\%$ & № & $\%$ & № & $\%$ & № & $\%$ & № & $\%$ \\
\hline Concordo & 22 & 34,3 & 20 & 33,3 & 15 & 23,7 & 12 & 20,3 & 08 & 12,9 \\
\hline Discordo & 26 & 40,0 & 28 & 46,6 & 40 & 63,4 & 34 & 60,6 & 45 & 72,5 \\
\hline Neutros & 6 & 25,7 & 10 & 20,1 & 08 & 12,9 & 10 & 19,1 & 09 & 14,6 \\
\hline Total & 64 & 100 & 58 & 100 & 63 & 100 & 56 & 100 & 62 & 100 \\
\hline
\end{tabular}

Tabela 2: Índice médio da caracterização do idialeto como sem sotaque, por estado. 
Os gaúchos, ao lado dos mineiros, foram os que obtiveram índices mais altos de concordância com a afirmação em teste: 33,3\% e 34,3\%, respectivamente, o que confirma, de certo modo, um sentimento por parte de ambos de estarem usando um dialeto-padrão. Uma vez que ambos se reconhecem como falantes de dialetos distintos, seria interessante saber como se vêem em relação ao dialeto usado pela mídia. É desnecessário lembrar aqui que a mídia tem um papel de força reconhecidamente padronizadora. Espera-se, portanto, que os dois grupos de falantes se identifiquem mais com a fala da mídia do que os demais.

Tomando-se o dialeto utilizado em noticiários de TV como representativo da fala da mídia, foi formulada a seguinte questão:

A fala dos jornalistas do Jornal Nacional reflete a fala da minha região. concordo: : :discordo

O resultado aparece no gráfico abaixo.

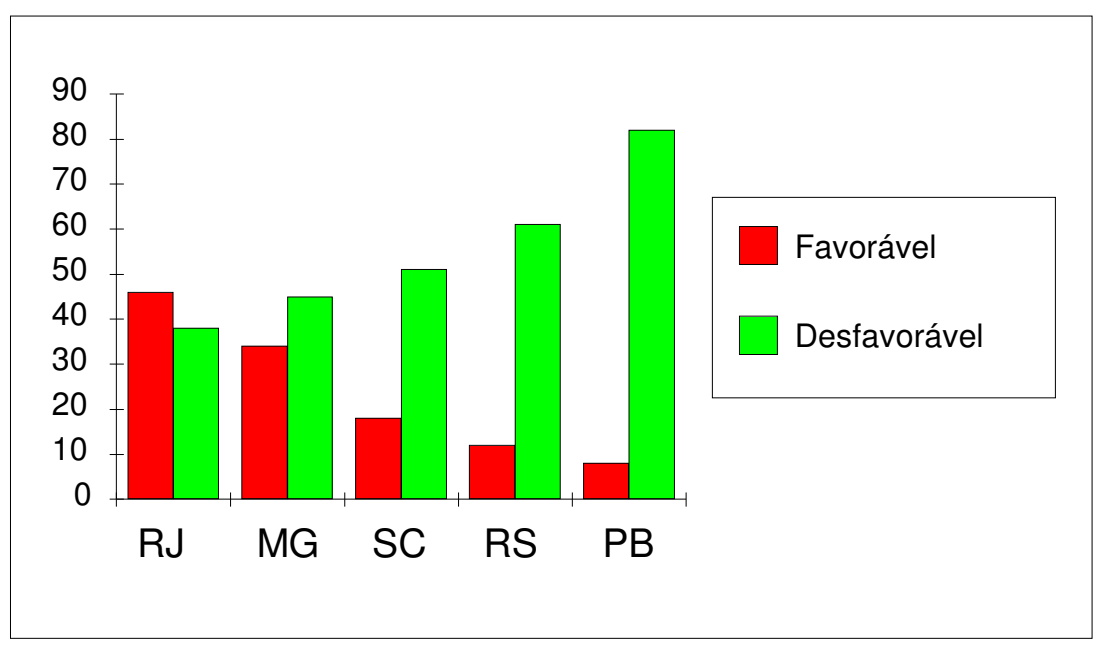

Gráfico 3: Índice médio, por estado, quanto à semelhança entre o próprio dialeto e a fala da mídia. 
Este gráfico mostra que quanto mais próximos do sudeste, mais os falantes sentem ser sua fala semelhante à fala da mídia: RJ (45.9\%), MG (34,4\%), SC (17,5\%), RS (11,9\%) e PB (8\%). Isto mostra que os falantes identificam a fala da mídia como ponto de referência.

Vejamos agora o cruzamento dos dados referentes à porcentagem de falantes que se dizem sem sotaque e a dos que concordam em que seu dialeto regional se aproxima da fala do JN. É de se esperar que tais porcentagens sejam semelhantes, já que a fala da mídia seria reconhecida como sem sotaque.

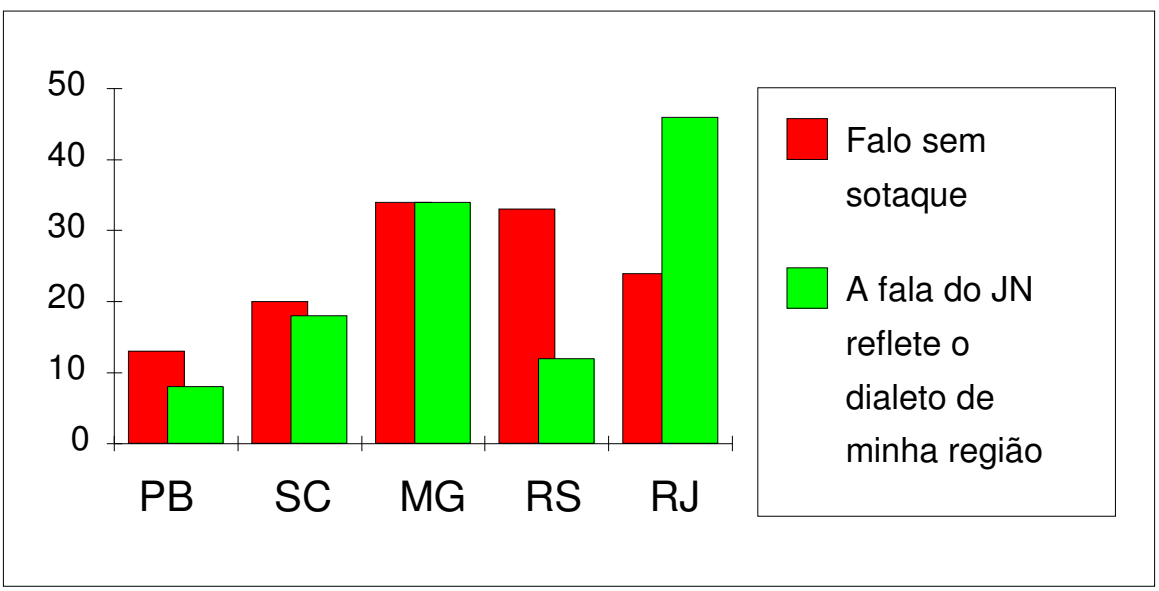

Gráfico 4: Comparação das porcentagens de falantes que julgam ser seu dialeto regional semelhante ao da mídia e, de falantes que se julgam falar sem sotaque, por estado.

Com base no perfil acima, pode-se ver que a expectativa se confirmou em três dos cinco estados estudados: as duas porcentagens são quase coincidentes, com uma leve superioridade da avaliação da própria fala. Quanto ao RJ e RS, entretanto, há diferenças: apenas no primeiro a avaliação do sotaque individual não supera a do dialeto regional; e no segundo nota-se certa contradição: ao mesmo tempo que os gaúchos estão entre os que 
mais se consideram sem sotaque (cf. gráfico 3), são eles que avaliam ser seu dialeto regional um dos mais distantes do JN.

Foi perguntado, então, ao informante se sua fala, considerada individualmente, se assemelhava à dos apresentadores do Jornal Nacional. O objetivo era verificar se a contradição se manteria. O resultado aparece no gráfico 5 . A questão formulada aparece abaixo.

Eu falo como os apresentadores do Jornal Nacional concordo discordo

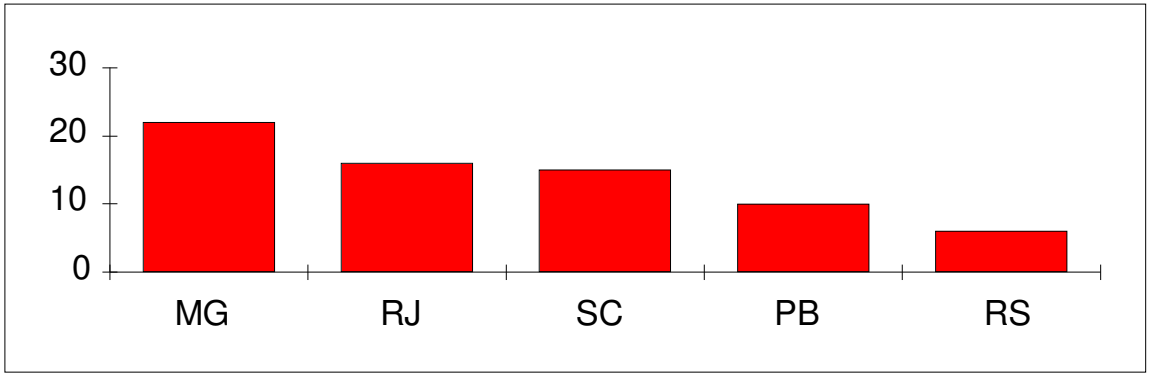

Gráfico 5: Índice médio de semelhança entre a fala individual e a fala da mídia, segundo a opinião dos falantes de cada, por estado.

Este gráfico mostra que a avaliação do idioleto se diferencia da avaliação do dialeto regional. A correlação entre distância geográfica e tipo de fala, refletida no gráfico 3, não foi mantida: os gaúchos se sentem mais distantes do que os paraibanos (6\% e 10\%, respectivamente), e os cariocas mais distantes que os mineiros (16\% e 22\% respectivamente). Parece haver aqui alguma interferência decorrente de se tomar a própria fala como objeto de análise. ${ }^{8}$

Apesar desta interferência, a comparação dos resultados apresentados no gráfico 3 e na tabela 2 permite conclusões interessantes sobre a percepção do próprio dialeto. É o que aparece no gráfico 6 . 


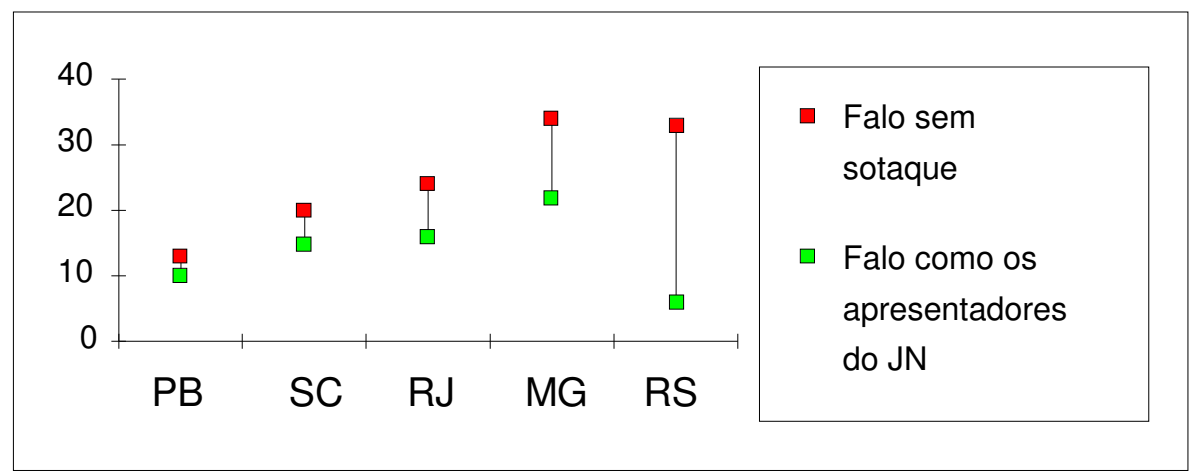

Gráfico 6: Comparação entre a porcentagem de falantes que assumem falar sem sotaque e a porcentagem de falantes que supõem ser sua fala semelhante à do JN, por estado.

Pode-se ver aqui certa harmonia entre os cinco estados: a avaliação quanto à ausência de sotaque supera o índice referente à semelhança com a fala dos apresentadores do JN. Quanto à distância entre os respectivos índices, observa-se que esta é maior no RS: os falantes que se consideram mais sem sotaque são os mesmos que se vêem mais distantes da fala da mídia. Assim, a contradição observada nos gráficos 3 e 6 se mantém. Uma explicação talvez possa ser buscada com base na noção de norma encoberta.

\subsection{Questionário de avaliação de amostras de fala}

O segundo questionário, cuja descrição apareceu na seção 2 deste artigo, visava a checar se a atitude manifestada em relação às questões do primeiro questionário se manteria quando os informantes fossem submetidos a amostras dos diferentes dialetos.

Os resultados a seguir referem-se apenas aos falantes belorizontinos, o que equivale a um dos cinco conjuntos de falantes dos dialetos avaliados. A seleção desses falantes deve-se ao fato de seu dialeto ter sido o mais rejeitado. ${ }^{9}$ A seguinte pergunta orienta a investigação descrita a seguir: será que o dialeto mineiro sofreria tamanha rejeição mesmo entre os mineiros? Vejamos. 
O primeiro dos quatro itens do teste buscava avaliar o reconhecimento de sotaques. Os seguintes índices foram obtidos:

Tabela 3: Porcentagem de identificação de seis dialetos por falantes mineiros

\begin{tabular}{|l|c|c|}
\hline & № & $\%$ \\
\hline Dialeto carioca & $26 / 31$ & 83,8 \\
\hline Dialeto gaúcho & $22 / 31$ & 70,9 \\
\hline Dialeto paulistano & $22 / 31$ & 70,9 \\
\hline Dialeto mineiro & $21 / 31$ & 67,7 \\
\hline Dialeto maranhense & $16 / 31$ & 51,6 \\
\hline Dialeto catarinense & $5 / 31$ & 16,1 \\
\hline
\end{tabular}

O dialeto mais reconhecido/identificado foi o dialeto carioca $(83,8 \%)$. O dialeto mineiro, embora fosse o dialeto local, obteve um índice que o coloca em terceiro lugar. Esse último resultado, embora curioso, foi semelhante ao encontrado por Rushmann (1984), com informantes paranaenses. Também naquele estado, o dialeto carioca foi o mais reconhecido e o dialeto paranaense ficou fora do primeiro lugar.

A explicação de Rushmann para os resultados foi a seguinte: o grau de reconhecimento é proporcional ao acesso ao referido dialeto via TV: dos seis dialetos analisados, os mais reconhecidos foram aqueles mais presentes na mídia. Veja-se que tal explicação, com base no acesso ao dialeto, embora possa dar conta do baixo grau de reconhecimento dos dialetos catarinense e maranhense na amostra aqui analisada, não é capaz de explicar porque o dialeto local não ocupa o primeiro lugar na escala. A não ser que o fator determinante seja a via de acesso, no caso a TV, o que implica que o reconhecimento exigiria uma representação, na maioria das vezes, estereotipada.

Vejamos agora, na tabela 4 , os resultados referentes à classificação dos dialetos quanto a ser agradável ou desagradável. 
Tabela 4: Porcentagem de apreciação positiva de seis dialetos por falantes mineiros

\begin{tabular}{|l|c|c|}
\hline & № & $\%$ \\
\hline Dialeto gaúcho & $25 / 29$ & 86,2 \\
\hline Dialeto paulistano & $22 / 29$ & 75,8 \\
\hline Dialeto maranhense & $20 / 28$ & 71,4 \\
\hline Dialeto mineiro & $20 / 30$ & 66,6 \\
\hline Dialeto carioca & $19 / 29$ & 65,5 \\
\hline Dialeto catarinense & $16 / 27$ & 55,1 \\
\hline
\end{tabular}

O dialeto considerado mais agradável foi o dialeto gaúcho. Esse resultado é consistente com os resultados do primeiro questionário, que não exigia a audição da fita.

O dialeto maranhense obteve o índice de 71,4\%. Esse índice é, entretanto, inferior aos dos dialetos paulistano e gaúcho, o que constitui um evidência contra a afirmação, até certo ponto corrente, de que o português mais bem falado no Brasil seria aquele falado no Maranhão.

Vejamos, agora, a tabela referente à presença de sotaque. Aparecem abaixo as respostas dadas à pergunta que pedia ao informante para assinalar qual dos falantes falava sem sotaque.

Tabela 5:Avaliação dos dialetos quanto à ausência de sotaque por falantes mineiros

\begin{tabular}{|l|c|c|}
\hline & № & $\%$ \\
\hline Falante 1 (mineiro) & 4 & 12,9 \\
\hline Falante 2 (maranhense) & 1 & 3,2 \\
\hline Falante 3 (carioca) & 0 & 0.0 \\
\hline Falante 4 (gaúcho) & 1 & 3,2 \\
\hline Falante 5 (catarinense) & 1 & 3,2 \\
\hline Falante 6 (paulistano) & 5 & 16,1 \\
\hline Nenhum dos falantes acima & 11 & 35,4 \\
\hline Não responderam & 8 & 26,0 \\
\hline Total & 31 & 100 \\
\hline
\end{tabular}


Para 35,4\% dos informantes, nenhum dos falantes fala sem sotaque. A porcentagem de $0 \%$ atribuída ao falante carioca indica que, aos ouvidos dos mineiros, este sotaque seria o mais marcado, enquanto que o paulistano, o menos marcado (16,1\%). Assim, este último poderia ser considerado o mais próximo ao da mídia.

Por fim, o índice avaliado foi o grau de correção. Pediu-se ao informante que, após ouvir amostras de cinco dialetos, apontasse a mais correta. O dialeto paulistano foi o que obteve índice maior $(93,1 \%)$, seguido de perto pelo dialeto gaúcho (90\%). O dialeto maranhense alcançou o índice de 76,6\%, inferior aos dialetos carioca, paulistano e gaúcho. Mais uma vez os resultados do teste que utilizou fita magnética coincidiram com o resultado do primeiro teste. Dentre os dialetos avaliados nos dois testes, o gaúcho recebeu índice mais alto.

O fragmento de entrevista com falante de Belo Horizonte obteve o índice mais baixo em relação à correção $(66,6 \%)$, enquanto que os fragmentos de entrevista com falantes de outros dialetos obtiveram índices superiores a $75 \%$. A porcentagem de falantes que não reconheceram esse dialeto e ainda assim o classificaram como correto foi exatamente a mesma $(66,6 \%)$.

Em resumo, o dialeto mineiro é avaliado como menos aceito, menos correto e o segundo menos agradável. Curiosamente seus falantes se reconhecem como aqueles cuja fala mais se aproxima à da mídia (cf. gráfico 5).

\section{CONCLUSÕES}

Este estudo, como se pode ver, constitui apenas um pouco mais do que um projeto piloto sobre alguns dos sotaques do português brasileiro. Há resultados muito curiosos que indicam serem necessárias análises mais detalhadas de modo a explicar as aparentes (?) contradições em relação aos dialetos mineiro e gaúcho. Seria também necessário: (a) ampliar o primeiro questionário de 
modo a inserir uma pergunta que avaliasse diretamente a fala da mídia quanto a possuir ou não sotaque; (b) aplicar o segundo questionário nas outras quatro capitais inicialmente previstas, pelo menos; e (c) explicitar os comportamentos das diferentes faixas etárias, ${ }^{10}$ apresentados aqui em conjunto. Estes dados, embora codificados, não apareceram nas tabelas e gráficos devido aos limites do presente artigo.

Apesar das limitações, os resultados acima revelaram que o dialeto preferido pelos próprios falantes é também o que é um dos mais aceitos pelos demais. Outro ponto importante é a sistematicidade das respostas. Nas cinco capitais, os questionários foram aplicados conforme as mesmas orientações e as respostas exibiram um padrão semelhante. Isso mostra que a metodologia é de modo geral válida e merece ser mantida, caso a amostra venha a ser ampliada e algumas perguntas reelaboradas.

\section{NOTAS}

${ }^{1}$ Uma versão inicial deste trabalho foi apresentada no XI Encontro Nacional da ANPOLL, em junho de 1996, na cidade de João Pessoa. Agradeço aos professores Paulino Vandresen (UFSC), Dermeval da Hora (UFPB), Ana Zilles (UFRS/Projeto VARSUL), Cláudia Roncaratti (UFRJ), Irenilde Pereira Santos (USP) pelo envio de dados e indicação de monitores. Agradeço aos monitores Cláudia Presser Sapé (UFRS), Ana Luzia Dias Pereira (UFSC), Adriana Karla de Andrade (UFPB), Eliane Mattos (UFRJ) e Marcelo Luiz de Camargos(UFMG) pela aplicação e envio dos testes.

${ }^{2}$ Conforme assinala Omdal (1995:86), "the concept of attitude is widespread both in social psychology and other scientific fields and among lay people. However, there is no general agreement on the definition of attitude, not even in social psychology".

${ }^{3}$ Estou aqui seguindo o critério utilizado para descrever as diferenças entre o falar das cidades de Tókio e de Tsuruoka, citados por Yoneda(1993) apud Chambers(1995:195). Embora reconheça que "dialeto" e "sotaque" sejam noções distintas, estarei utilizando um termo pelo outro no decorrer deste trabalho.

${ }^{4}$ Ver íntegra do primeiro questionário no anexo 1. O segundo questionário aparece no próprio texto. 
${ }^{5}$ Foi solicitado aos monitores que selecionassem informantes de classe média: os da faixa de 15 a 17 anos deveriam ser alunos de colégios particulares e os informantes universitários deveriam ser de cursos prestigiados. Além disso, foram solicitados os seguintes dados de cada informante:

Assinale com um x o que você tem em sua casa.

( ) 1 televisão

( ) computador

( ) 1 quarto

( ) 2 quartos

( ) 3 quartos

( ) 1 sala

( ) 2 salas

( ) 2 televisões

( ) 1 carro antigo
( ) geladeira

( ) vídeo-cassete

( ) máquina de lavar

( ) forno micro-ondas

( ) 1 banheiro

( ) 2 ou mais banheiros

( ) 1 ou mais carros novos

$\mathrm{Na}$ quantificação foram atribuídos valores a cada item, um ponto, dois pontos ou três pontos conforme o item. O total de pontos distribuídos foi 27. Estabeleceu-se então a seguinte escala: quem obteve até 10 pontos, classe média baixa; quem obteve até 20 pontos, classe média-média; e quem obteve acima de 21 , classe média alta.

${ }^{6} \mathrm{~A}$ opção por esse tipo de cálculo se deve à tentativa de se manter o mesmo critério utilizado por Almeida (1979) pelas razões já apontadas. Sobre outros modos de quantificação ver Summers, G.(1977).

${ }^{7}$ Agradeço ao parecerista por esta sugestão.

${ }^{8}$ Trudgill (1972:184, cidato por Omdal, 1995) comenta, a propósito de as pessoas não serem capazes de dizer quais sejam realmente suas reais atitudes: "many informants who initially stated that they did not speak properly, and would like to do so, admitted, if pressed, that they perhaps would not really like to, and that they would almost certainly be considered foolish, arrogant or disloyal by their friends and family if they did."

${ }^{9}$ Ver tabela i, cujos índices serviram de base para a média que aparece no gráfico 1. Tabela i: Porcentagem de aceitação dos cinco dialetos, por todos os informantes.

\begin{tabular}{|l|rr|rr|rr|rr|rr|}
\hline & \multicolumn{2}{|c|}{ RJ } & \multicolumn{2}{c|}{ MG } & \multicolumn{2}{c|}{ SC } & \multicolumn{3}{c|}{ RS } & \multicolumn{2}{c|}{ PB } \\
\cline { 2 - 14 } & \multicolumn{1}{|c|}{ № } & $\%$ & \multicolumn{1}{|c|}{ № } & $\%$ & \multicolumn{1}{c|}{ № } & $\%$ & № & $\%$ & № & $\%$ \\
\hline Dialeto Carioca & $13 / 63$ & 20.5 & $1 / 54$ & 1.8 & $6 / 58$ & 10.3 & $3 / 59$ & 4.98 & $3 / 61$ & 4.9 \\
\hline Dialeto Gaúcho & $14 / 63$ & 22.1 & $4 / 54$ & 7.4 & $4 / 57$ & 7.0 & $24 / 60$ & 40.0 & $3 / 62$ & 4.8 \\
\hline Dial. Catarinense & $4 / 63$ & 6.4 & $2 / 54$ & 3.7 & $20 / 57$ & 35.1 & $2 / 60$ & 3.3 & $2 / 62$ & 3.2 \\
\hline Dialeto Paraibano & $1 / 63$ & 1.5 & $1 / 54$ & 1.8 & $6 / 57$ & 10.5 & $4 / 60$ & 6.6 & $9 / 61$ & 14.6 \\
\hline Dialeto Mineiro & $0 / 63$ & 0 & $16 / 54$ & 29.5 & $0 / 57$ & 0 & $2 / 60$ & 3.2 & $0 / 61$ & 0 \\
\hline
\end{tabular}


${ }^{10}$ Motti (1984:113-4), ao estudar o prestígio de sotaques brasileiros, comparou o comportamento de três faixas etárias e concluiu que "as faixas etárias, coesas em alguns pontos, manifestam divergências, demonstrando os graus de desenvolvimento e equilíbrio" dos diferentes grupos.

\section{REFERÊNCIAS BIBLIOGRÁFICAS}

ALMEIDA, M.J.A. Étude sur les attitudes linguistiques au Brésil. Université de Montréal, Thèse de Philosophiae Doctor. 1979.

CHAMBERS, J. K. Sociolinguistic Theory. Oxford/ Cambridge, Blackwell. 1995.

FASOLD, R. Language Attitudes in The Sociolinguistics of Language. Oxford/ Cambridge.Blackwell. 1984.

FISHBEIN. A consideration of beliefs, attitudes and their relationships. In Steiner, M., D. Ivan, ed. Current Studies in Social Psychology. New York, Holt, Rinehart and Winston, 1965:107-119.

MOTTI, S. T. Prestígio Atribuído a Diversos Sotaques por Parte de Determinada Comunidade. Fragmenta Linguistica 3, UFPR. 1984.

OMDAL, H. Attitudes toward spoken and written Norwegian. Int'l. J. Soc. Lang. 115, 1995:85-106.

OSGOOD, SUCI \& TANNENBAUM. The Measurement of Meaning. Urbana, University of Illinois. 1957.

RUSHMANN, M. C. F. Prestígio de Sotaques. Fragmenta Linguistica 3, UFPR. 1984.

SANTOS, E. A Transmissão ao Educando de Crenças e Atitude Linguísticas. Tese de Doutoramento, Rio de Janeiro, UFRJ. 1980.

SUMMERS, G.F. (org) Attitude Measurement. London, Kershaw Publishing Company, 1979.

TRUDGILL, P. Sex, covert prestige and linguistic change in the Urban British English of Norwich. Language in Society 1, 1972:179-195.

YONEDA, M. Survey of standardization in Tsuruoka City, Japan: Comparison of results from three surveys conducted at twenty-year intervals. Paper presented at Methods VIII: International Conference in Dialectology. University of Victoria, British Columbia. 1993. 


\section{ANEXO 1}

\section{FICHA}

Nome:

Sexo:

Idade:

Profissão:

Cidade natal:

Anos de residência nesta cidade:

Bairro:

Escolaridade:

Assinale com um x o que você tem em sua casa.
( ) 1 televisão
( ) computador
( ) 1 quarto
( ) 2 quartos
( ) 3 quartos
( ) 2 salas
( ) 2 televisões
( ) 1 carro antigo

( ) geladeira
( ) vídeo-cassete
( ) máquina de lavar
( ) forno micro-ondas
( ) 1 sala
( ) 1 banheiro
( ) 2 ou mais banheiros
( ) 1 carro novo

\section{Questionário}

Instrução: Damos uma lista de pares de palavras contrárias com seis espaços entre elas. Você pode marcar a sua opinião com um (x) no espaço que melhor corresponde ao que você pensa.

Exemplo: Supondo que o par de palavras seja "agradável/desagradável", você pode marcar assim:

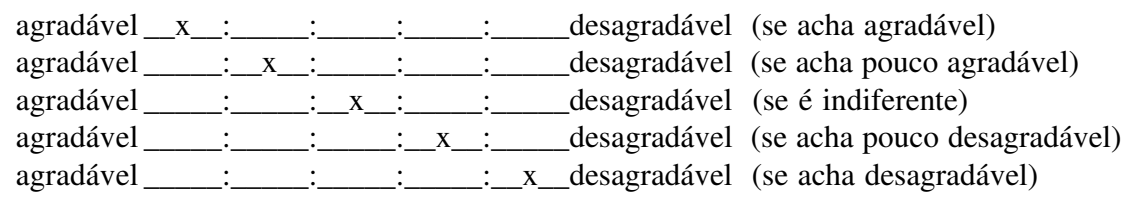

Advertência: 1) Só deve haver um x em cada linha.

2) Coloque o $\mathrm{x}$ no meio dos espaços. 


\section{Questões}

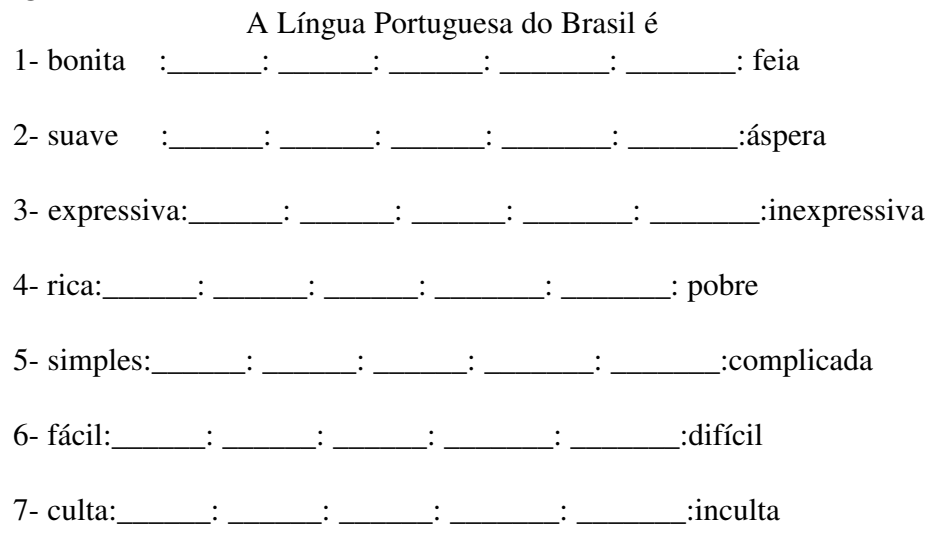

2) As pessoas do meu Estado falam como os apresentadores do Jornal Nacional. concordo: : :discordo

3) As classes alta, média e baixa falam todas da mesma maneira. concordo: _ _

10) É importante falar bem a língua. concordo: : :discordo

11) Eu falo como a classe alta concordo: : : ___ : $\quad$ :

12) Os gaúchos falam o melhor português do Brasil. concordo: : :discordo

13) O modelo carioca deveria ser seguido pelos brasileiros em geral. concordo: :discordo

14) Gente rica fala melhor que gente pobre.

concordo: :<smiles>C1CCCC1</smiles>
: :discordo

15) Todos os Estados do Brasil deveriam falar como os paraibanos. concordo: : $:$ discordo

16) A língua portuguesa autêntica é a de Portugal. concordo: :discordo

17) Todos os brasileiros deveriam falar como os gaúchos. concordo: : : : :discordo 
18) A língua portuguesa não é muito falada no exterior porque ela é muito difícil. concordo: :discordo

19) Eu falo como a classe média. concordo:

20) Todos os brasileiros deveriam falar como os paulistanos. concordo: :discordo

21) A pessoa que usa a língua culta fala bem.

concordo: : :discordo

22) Eu falo como a classe baixa.

concordo: :discordo

23) Todos os brasileiros deveriam falar como os goianos. concordo: :discordo

24) Eu falo como os apresentadores do Jornal Nacional, da Globo. concordo: : discordo

25) Deveríamos melhorar a língua falada em Minas Gerais. concordo: : : :discordo

26) Falar bem é falar como os paranaenses. concordo: : :discordo

27) Eu falo pior em casa.

concordo: : :discordo

28) Todos os brasileiros deveriam falar como os mineiros. concordo: : : : :discordo

29) Entre amigos é que eu falo pior. concordo: : : :discordo

30) Eu falo melhor na escola. concordo:

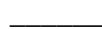
: $:$ discordo

31) Gente da roça fala melhor que gente da cidade. concordo: :discordo

32) Eu falo sem sotaque algum.

concordo: : : _ _ _ discordo 
33) Quem fala melhor o português são os catarinenses.

concordo: : : : :discordo

34) A fala dos jornalistas do Jornal Nacional reflete a fala da minha região. concordo: : :discordo

Assinale com $\mathrm{x}$ :

O ESTADO QUE FALA MELHOR O PORTUGUÊS É:

\begin{tabular}{llll}
\hline pronúncia & gramática & vocabulário & entoação \\
\hline
\end{tabular}

1. Paraíba

2. Santa Catarina

3. Bahia

4. Minas Gerais

5. Rio de Janeiro

6. São Paulo

7. Paraná

8. Rio Grande do Sul

9. Goiás

10.Maranhão

Numere de 1 a 5 aquele profissional que melhor fala o português :

( ) advogado ( ) jornalista ( ) faxineiro ( ) médico ( ) comerciante 